Cerebrovasc Dis 2011;32:123

DOI: $\underline{10.1159 / 000329528}$

\section{Is Stroke Etiology a Determining Factor for the Pattern of Secondary Immune Alterations?}

\section{Alexander Dressel \\ Department of Neurology, Ernst Moritz Arndt University, Greifswald, Germany}

The efforts to unravel the secondary consequences of acute stroke have led to investigations of the immunological alterations induced by stroke. By now, multiple components of the immune system have been identified that contribute to brain lesion development and/or affect the clinical outcome of stroke patients.

Peripheral immune suppression, mainly affecting lymphocytes and monocyte function, has been shown to be an important predictor of bacterial infections, especially pneumonia $[1,2]$. Most authors agree that the occurrence of pneumonia will affect the clinical outcome of patients [3].

In addition, an inflammatory infiltrate develops at the site of the stroke lesion. This immune response in the brain itself has dual consequences: on the one hand, proinflammatory cascades with the release of proinflammatory cytokines mediate neurotoxicity, thus increasing infarction volume; on the other hand, regulatory $(\mathrm{T})$ cells dampen the immune response and inhibit brain injury $[4,5]$.

Complement is involved in several aspects of the pathogenesis of stroke: complement factor C3 is synthesized in the liver as an acute phase protein and therefore increased in many inflammatory conditions. Its activated cleavage product $\mathrm{C} 3 \mathrm{a}$ acts as proinflammatory mediator. C3 deposits have been found in atherosclerotic plaques. In addition, both C3 and C3a have been implicated in ischemia-reperfusion injury [6]. As recently reviewed by Yanamadala and Friedlander [6], there is also evidence to support neuroprotective features of $\mathrm{C} 3 \mathrm{a}$ in stroke and other types of brain injury.

The majority of studies in human stroke have stratified patients according to stroke severity but not stroke etiology. In this issue of Cerebrovascular Diseases, Stokowska et al. [7] report differences in complement activation in large-vessel disease (LVD) stroke and cryptogenic stroke.

They investigated serum C3 and C3a complement levels in stroke due to LVD and cryptogenic stroke using samples from the Sahlgrenska Academy Study on Ischemic Stroke in the acute phase of ischemic stroke and 3 months later. These data were then correlated with clinical outcome at 3 months and 2 years.

The authors found a persisting increase in C3 in both subtypes of stroke. C3a, though, normalized in cryptogenic stroke patients but remained elevated in LVD compared to controls at 3 months. These data could relate to the underlying pathology or the size of the infarction since complement activation is known to be associated with both atherosclerosis and ischemia-reperfusion injury [8].

LVD patients with high C3 levels at 3 months were at risk for an unfavorable outcome. The association seen in the cryptogenic stroke patients for $\mathrm{C} 3 \mathrm{a}$ with outcome was lost in a multivariate regression model.

As addressed by the authors themselves, there are limitations to this study: as the data for the LVD and cryptogenic stroke patients were determined more than a year apart, a direct comparison of both groups is not possible. Also data on preceding infections and secondary infections as well as infarction volume were not available. All of those factors may alter C3 and C3a levels in peripheral blood. More robust data will be needed to test whether C3 or C3a levels or other members of the complement system reflect stroke severity and can indeed serve as an independent predictor for clinical outcome.

The merit of the study by Stokowska et al. [7] comes from the important observation that distinct stroke etiologies may also result in distinct activation patterns of the complement system. As complement is closely involved in the activation of the immune system, these differences may result in distinct activation patterns of the immune system depending on the stroke etiology. If confirmed, studies aiming to decipher the immune response in stroke should not only stratify their patient cohorts according to stroke severity but may need to control for stroke etiology and complement activation, too.

\section{References}

1 Prass K, Meisel C, Hoflich C, Braun J, Halle E, Wolf T, Ruscher K, Victorov IV, Priller J, Dirnagl U, Volk HD, Meisel A: Stroke-induced immunodeficiency promotes spontaneous bacterial infections and is mediated by sympathetic activation reversal by poststroke $\mathrm{T}$ helper cell type 1-like immunostimulation. J Exp Med 2003;198:725-736.

-2 Vogelgesang A, Grunwald U, Langner S, Jack R, Broker BM, Kessler C, Dressel A: Analysis of lymphocyte subsets in patients with stroke and their influence on infection after stroke. Stroke 2008;39:237-241.

- 3 Vermeij FH, Scholte op Reimer WJ, de Man P, van Oostenbrugge RJ, Franke CL, de Jong G, de Kort PL, Dippel DW: Stroke-associated infection is an independent risk factor for poor outcome after acute ischemic stroke: data from the Netherlands stroke survey. Cerebrovasc Dis 2009; 27:465-471.

4 Gee JM, Kalil A, Shea C, Becker KJ: Lymphocytes: potential mediators of postischemic injury and neuroprotection. Stroke 2007;38:783-788.

5 Liesz A, Suri-Payer E, Veltkamp C, Doerr H, Sommer C, Rivest S, Giese T, Veltkamp R: Regulatory T cells are key cerebroprotective immunomodulators in acute experimental stroke. Nat Med 2009;15:192-199.

6 Yanamadala V, Friedlander RM: Complement in neuroprotection and neurodegeneration. Trends Mol Med 2010;16:69-76.

-7 Stokowska A, Olsson S, Holmegaard L, Jood K, Blomstrand C, Jern C, Pekna M: Plasma C3 and C3a levels in cryptogenic and large-vessel disease stroke: associations with outcome. Cerebrovasc Dis 2011;32:114-122.

-8 Széplaki G, Varga L, Füst G, Prohászka Z: Role of complement in the pathomechanism of atherosclerotic vascular diseases. Mol Immunol 2009;46:2784-2793.

\section{KARGER}

Fax +41613061234 E-Mail karger@karger.ch www.karger.com
() 2011 S. Karger AG, Basel

$1015-9770 / 11 / 0322-0123 \$ 38.00 / 0$

Accessible online at:

www.karger.com/ced
Alexander Dressel

Universitätsmedizin Greifswald

Klinik und Poliklinik für Neurologie

Sauerbruchstrasse, DE-17475 Greifswald (Germany)

E-Mail adressel@uni-greifswald.de 